\title{
MMW-HOTLINE
}

Leser der MMW können sich mit allen Fragen zur Abrechnung und Praxisführung an Helmut Walbert, Facharzt für Allgemeinmedizin, Würzburg, wenden. Sie erreichen ihn jeden Donnerstag von 13 bis 15 Uhr unter der kostenlosen Rufnummer (0800) 2379830 oder per E-Mail: w@lbert.info.

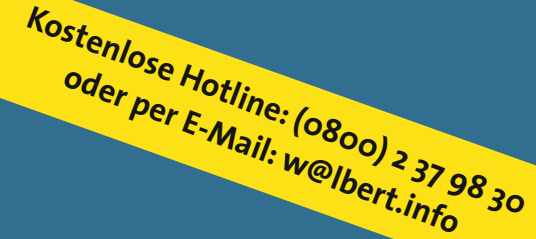

Helmut Walbert

Allgemeinarzt, Medizinjournalist und Betriebswirt Medizin

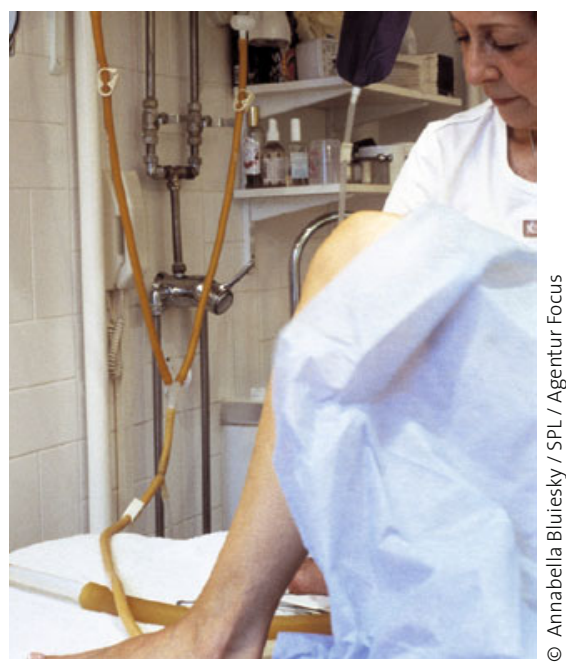

Colon-Hydrotherapie - lohnt sich der Aufwand?

Frage von Dr. P. W. Allgemeinarzt, Naturheilkunde, München:

Ich möchte Colon-Hydrotherapie anbieten. Wie kann ich diese Individuelle Gesundheitsleistung abrechnen?

Individuelle Gesundheitsleistung

\section{Wie rechne ich die Colon-Hydrotherapie ab?}

Antwort: Die Colon-Hydrotherapie ist keine eindeutig und klar definierte Behandlungsmethode. Sie wird auch mit und ohne Krankheitssymptomatik angewendet. Sie kann analog nach GOP A 533, Subaquales Darmbad, 150 Punkte, abgerechnet werden. Da die GOP 533 eine technische Leistung ist, kann sie nur bis zum 1,8-fachen Satz, also $€ 8,74$ gesteigert werden. Mit Begründung: Ausführung als Colon-Hydrotherapie kann sie auch mit dem 2,5-fachen Satz $(€ 21,85)$ verrechnet werden.

Selbstverständlich können nach \$10 der GOÄ die Spülbestecke und Spüllösungen zusätzlich verrechnet werden. Zur reinen technischen Leistung kommen noch eine Reihe weiterer Leistungen wie Beratung nach GOP 1 oder 3, Laborleistungen, Untersuchung nach GOP 8, Ganzkörperstatus, oder GOP 7, Untersuchung Organsystem Bauchorgane.

Wichtig erscheint mir vor allem, vor Start dieser Leistung eine Kosten-Nutzen-Rechnung anzustellen. Es handelt sich hier um eine aufwendige Leistung in Bezug auf die Material- und die Personalkosten. Wenn Sie erst investieren müssen, kann es schnell eine unwirtschaftliche Leistung sein!

\section{Was kann ich für die Kopien meiner Unterlagen verlangen?}

Frage von Dr. med. W. D. E., Allgemeinarzt, Ochsenfurt:

Eine Patientin möchte für die Krankenkasse einen kompletten Ausdruck der Verordnungen und Behandlungsdaten für dieses Jahr, um die Zuzahlungsgrenze überprüfen zu lassen. Wie verrechne ich diese Leistung?

Antwort: Diese Leistung ist keine Leistung, die die Krankenkasse anfordert. Damit ist sie auch nicht zulasten der GKV abre- chenbar. Sie lassen sich die Kopien nach der GOÄ erstatten. Angemessen ist hier ein Betrag von 50 Cent pro Kopie. Falls Sie umsatzsteuerpflichtig sind, zusätzlich $19 \%$ Mehrwertsteuer.

Im Prinzip brauchen Sie aber gar nicht aktiv zu werden. Die Patientin möchte wohl die Belastungsgrenze feststellen lassen. Hierzu soll sie zur Krankenkasse gehen und dort die Quittungen über die gezahlte Kassengebühr, die Zuzahlungen in der
Apotheke und bei sonstigen Leistungserbringern sowie die Zuzahlung im Krankenhaus (10 Euro pro Tag, höchstens 28 Tage pro Kalenderjahr) vorlegen. Die Krankenkasse wird der Patientin dann einen Vordruck zur Bescheinigung der chronischen Erkrankungen mitgeben. Dieser vereinbarte Vordruck (Muster 55) wird nach GOP 01610 , Bescheinigung zur Feststellung der Belastungsgrenze, abgerechnet und mit fürstlichen 1,40 € vergütet. 